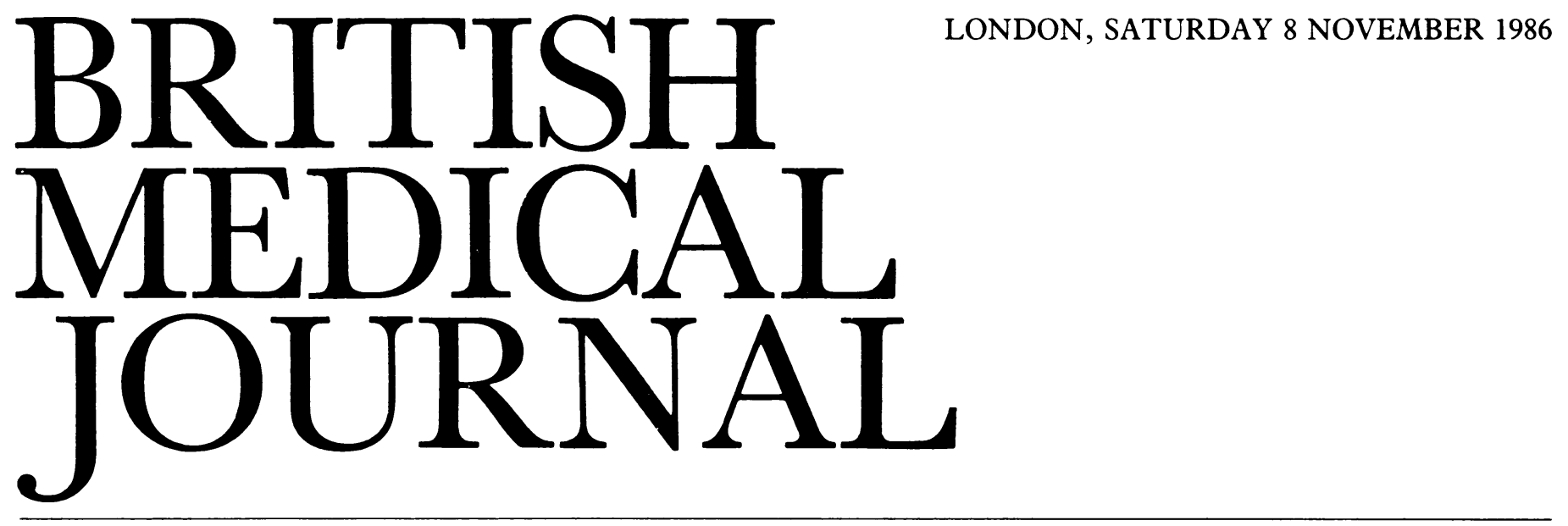

\title{
Biosynthetic growth hormone: whom to treat?
}

During the past 18 months the saga of therapeutic human growth hormone has gone through several twists, many of which have been described in the $B M \mathcal{F} .^{1}$ Two questions remain: what therapeutic substances are available, and in whom should they be used?

Biosynthetic methionyl human growth hormone (somatrem) was developed using the then available biotechnology, which left an extra aminoterminal methionine coded for by the start codon in the synthetic gene. ${ }^{2}$ It could not be removed by conventional chemical methods because further cleavages would have occurred at the three other methionines in the molecule. This problem has been resolved in two ways. Most commonly the human growth hormone gene has been modified to produce prohormone in Escherichia coli. After extraction the prohormone is cleaved enzymatically to yield mature human growth hormone with the correct 191 amino acid sequence. Alternatively the gene can be expressed in mammalian cells that secrete a mature 191 amino acid hormone.

Thus within the next year there should be a virtually unlimited supply of several different types of biosynthetic human growth hormone with a sequence identical with that of the hormone produced by the human pituitary. Whether the tertiary structures of the hormones are identical remains to be seen.

How should this hormone be used? Treating conventional growth hormone deficiency-either as a primary idiopathic disorder or as secondary to intracranial tumours or radiotherapy-is well established. In contrast, there is still much doubt about using the hormone in children whose shortness cannot be attributed to conventional growth hormone deficiency. It has been used in Turner's syndrome and seems to be beneficial at least in the short term. Preliminary reports suggest that methionyl human growth hormone alone accelerates growth and that greater acceleration is achieved if it is combined with oxandrolone. ${ }^{3}$ Whether this effect will be maintained is still uncertain.

More contentious is whether the hormone should be used in short children with no definable abnormality. Four recent studies have shown a significantly increased growth rate in a variable proportion of short children with normal human growth hormone secretion and no stigmata of other syndromes given the hormone. ${ }^{47}$

Most of the studies, however, reported only six months of treatment, and all were uncontrolled. Any assessment over less than 12 months can be criticised: growth rates fluctuate seasonally, ${ }^{8}$ and the acceleration in growth rate could be entirely due to seasonal variation. Short term measurements also produce more errors, making interpretation more difficult. ${ }^{9}$

The absence of controls is more difficult to resolve. In Britain the Health Services Human Growth Hormone Committee attempted to tackle this issue about two years ago by starting a placebo controlled trial of treatment with human growth hormone in normal short children. Unfortunately this trial had to be aborted shortly after six months because of the withdrawal of pituitary human growth hormone in May 1985. Generally the treated patients showed a modest increase in growth rate compared with the placebo group, but because of considerable heterogeneity of response none of the effects was significant (C Buchanan, R D G Milner, personal communication). A much larger trial is now in progress.

In children deficient in growth hormone who have been treated over the past 25 years the only important side effects have been the development of antibodies to some of the earlier preparations ${ }^{10}$ and the transmission of CreutzfeldtJakob disease. ${ }^{11}$ No side effects have been attributable to the biological action of the hormone itself. If, however, human growth hormone is used in endocrinologically normal children, possibly in larger doses, there may be side effects. The development of antibodies would be disastrous if they cross reacted with the patient's own hormone, but this seems to occur only very rarely. Further possible complications include the development of diabetes, hypertension, and all the other problems of acromegaly. Such complications have not been seen, but they remain possibilities, although the quantity of growth hormone secreted in the average patient with acromegaly probably exceeds considerably the proposed doses of human growth hormone.

Biosynthetic human growth hormone will replace both pituitary and the intermediate methionyl human growth hormone and will be used to treat growth hormone deficiency of known aetiology. Some endocrinologically normal short children may also benefit from treatment, but predicting who may respond is difficult. Well designed and controlled studies of adequate size are needed, and all such children should be treated according to similar protocols. Studies 
lasting several years are also needed to see if permanent changes in growth patterns can be achieved.

Professor of Child Health and Growth,

M A PREECE

Institute of Child Health

London WCIN $1 E H$

1 Milner R. Growth hormone 1985. Br Med f 1985;291:1593-4

2 Ross M. Production of medically important polypeptides using recombinant DNA technology. In: Gueriguian JL, ed. Insulins, growth hormone, and recombinant DNA technology. New York: Raven Press, 1981:33-48

3 Rosenfeld R, Hintz R, Johanson A, Genentech Collaborative Group. Prospective, randomized trial of methionyl growth hormone and/or oxandrolone in Turner syndrome. Pediatr Res 1985;19:620.

4 Frazer T, Gavin J, Doughaday W, Hillman R, Weldon V. Growth hormone-dependent growth failure. F Pediatr 1982;101:12-5.

5 Van Vliet G, Styne D, Kaplan S, Grumbach M. Growth hormone treatment for short stature. N Englf Med 1983;309:1016-22.

6 Grunt J, Howard C, Doughaday W. Comparison of growth and somatomedin C responses following growth hormone treatment in children with small-for-date short stature, significant idiopathic short stature and hypopituitarism. Acta Endocrinol (Copenh) 1984;106:168-74.

7 Gertner J, Genel M, Gianfredi S, et al. Prospective clinical trial of human growth hormone in short children without growth hormone deficiency. F Pediatr 1984;104:172-6.

8 Marshall $W$. The relationship of variations in children's growth rates to seasonal climatic variations. Ann Hum Biol 1975;2:243-50.

Barratt T, Brover M, Chantler C, et al. Assessment of growth. Am $\mathcal{F}$ Kidney Dis 1986;7:340-6.

10 Preece M. Experience of treatment with pituitary-derived hGH with special reference to immunological aspects. In: Milner RDG, Flodh $\mathrm{H}$, eds. Immunological aspects of human growth hormone. Oxford: Medical Education Services, 1986:9-16.

11 Preece M. Creutzfeldt-Jacob disease: implications for growth hormone deficient children Neuropathol Appl Neurobiol (in press).

\section{A better way to detect growth failure}

Most doctors are familiar with growth charts for height and weight that have a 10 th centile (this means that $10 \%$ of normal children have a height or weight as low as or lower than that). Such charts are called distance charts. Fewer doctors, however, seem to be familiar with velocity charts, which show how fast a child is growing. Yet these charts are more important because a single point on a distance chart is not a good way of determining the normality of growth, which is an active process.

The difference between two successive points on a distance chart shows how much a child has grown and can be turned into a velocity by dividing by the time interval. This value can then be entered on to a velocity centile chart, ${ }^{1}$ whichjust like a distance chart-is marked with centiles. The centiles on a velocity chart are specific to a particular time interval, usually one year. If measurements are taken at shorter intervals an annual growth velocity can be calculated -but the centiles may be as much as twice as wide as those for an annual increment because the measurement errors have been magnified and there may be seasonal effects on growth.

Points on a distance chart for a single child are highly correlated: a child who is small on one occasion will almost certainly be small on the next. A normal child will thus tend to follow a particular centile, and deviations of growth from a centile are difficult to detect by eye. This is one reason for calculating velocity in the clinic because there is a difference when successive points are plotted on a velocity chart: in fact, successive velocities are hardly correlated at all. A child whose velocity was consistently at the 30 th centile for years would turn into a dwarf, and one with a velocity consistently on the 70th centile would become a giant. Thus the probability of two successive velocities in a normal child falling on the 25 th centile is only around $0.25 \times 0.25(0.0625)$
- that is, only $6 \cdot 25 \%$ of healthy children will grow as slowlyo as this over the whole of a two year period.

Because successive velocities are independent one cut of may be taken as an indication for immediate action andanother as a warning signal. If a third centile velocity chosen for immediate action the chances of investigating $\overline{\overline{\mathrm{a}}}$ normally growing child are only $3 \%$. A suitable warning limi could be at the 25 th centile. A child with a velocity below thiff but not as low as the action limit should be followed up and iq the next velocity also falls below the warning limit actio should be taken. A chart incorporating this idea is available.

Powerful treatments for altering growth rates are increase ingly available, and not investigating healthy children is as important as detecting failing growth. Careful interpretatio of growth data will help in both directions.

C G D BROo Consultant paediatricia

P C HINDMARS留

Middlesex Hospital,

London W1N 8AA

Paediatric research fellow

M J R HEAL Kٔ

London School of Hygiene and Tropical Medicine,

London WCIE 7HT

Professor of medical statisticis

Tanner JM, Whitehouse RH. Longitudinal standards for height, weight, height velocity, weigto

velocity, and stages of puberty. Arch Dis Child 1976;51:170-9.
Brook CGD. Earlier recognition of abnormal stature. Arch Dis Child 1983;53:840. [Available Middlesex hight velocity assessment chart from Castlemead Publications, Ware, Herts SGI 9PY.]

\section{Acquired cystic disease of the kidney: serious or irrelevant?}

That the kidneys of some patients with end stage renal failuri develop multiple cysts has long been recognised, ${ }^{1}$ but only ip 1977 did Dunnill and others coin the term "acquired cystie disease of the kidney." They performed necropsies on 3 (a) patients who had been treated with long term haemodialysis (none of them because of primary cystic diseases of the kidney) and discovered that 14 had multiple cortical cysts:Since then many studies have described such cysts ${ }^{3-15}$ : these range in size from $1 \mathrm{~mm}$ to over $2 \mathrm{~cm}$, occur in both the medulla and the cortex, and may replace much of the parenchyma. But do they matter? Are they a pathologicals irrelevancy or an important clinical problem? The latesp evidence suggests thay they probably do matter.

Acquired cystic disease of the kidney has now beet described in patients having haemodialysis or peritoneat dialysis and becomes increasingly common and severe as the duration of dialysis increases. It is more common in male patients and is unrelated to age. ${ }^{916}$ Whether some primar $\$$ renal diseases are particularly associated with acquired cystic disease of the kidney is not clear. ${ }^{214}$ Histological studies show that the cysts communicate with both tubules and glomeru $\vec{p}$ and may be lined with atypical (possibly neoplastic) cells. ${ }^{511}$ \% Solid tumours occur, and distinguishing between adenom and adenocarcinoma is difficult. ${ }^{2}$ Suggested aetiologie include a response to ischaemia, ${ }^{7}$ occlusion of the tubules bo fibrosis or oxalate, ${ }^{2}$ the effect of toxins absorbed from 